LEADING ARTICLE

\title{
Relevance of volume and proximal extent of reflux in gastro- oesophageal reflux disease
}

\section{Sifrim}

In patients with gastro-oesophageal reflux disease (GORD), oesophageal and extraoesophageal symptoms are traditionally attributed to increased contact time between the mucosa and refluxates. However, the volume of reflux may be important by increasing the total amount of highly concentrated damaging substances, either by prolonging distal mucosal exposure or by expanding to more proximal areas. To date, it has not been possible to accurately measure the volume of gastro-oesophageal reflux. Determination of the volume of reflux will help to better understand the pathophysiology of GORD and to evaluate the efficacy of antireflux treatments.

Correspondence to: Professor Daniel Sifrim Faculty of Medicine KU Leuven, Lab G-I Physiopathology, O\&N Gasthuisberg, 7th floor, Herestraat 49, 3000

Leuven, Belgium;

Daniel.Sifrim@

med.kuleuven.ac.be

Received 1 July 2004 Accepted for publication 14 July 2004
। n patients with gastro-oesophageal reflux disease (GORD), oesophageal and extraoesophageal symptoms are traditionally attributed to increased contact time between the mucosa and refluxates. Such exposure is expressed as percentage of time the mucosa is exposed to a predetermined concentration of $\mathrm{H}^{+}$, bile acids, or pepsin without considering the volume of the refluxate.

It is a popular belief that some patients with GORD have large volume reflux events, mostly in the supine position, whereas other patients have predominantly upright small volume reflux events. This concept comes from endoscopic and surgical observations in patients with a permanent open cardia, or from interpretation of pH-metry studies with prolonged clearance of acid. ${ }^{12}$ However, endoscopic and surgical observations are unlikely to represent spontaneous reflux events under physiological conditions, and prolonged acid clearance during pH-metry may be due to superimposed small volume reflux events. ${ }^{3}$

Technical difficulties have precluded accurate estimation of reflux volume. Instead, multiple studies have tried, as a surrogate, to associate extraoesophageal symptoms of GORD with detection of acid reflux in the proximal oesophagus or pharynx. Proximal oesophageal and hypopharyngeal acid exposure were increased in patients with laryngeal signs of $\mathrm{GORD}^{4-7}$ However, proximal oesophageal reflux may occur in normal subjects and this measurement has low sensitivity and reproducibility. ${ }^{8}$ Moreover, in a retrospective study by Cool et al, putatively GORD related respiratory and ENT symptoms did not occur more frequently in patients with abnormal proximal acid reflux. ${ }^{9}$ Recent studies
Gut 2005;54:175-178. doi: 10.1136/gut.2004.043984

using pharyngeal impedance-pH recordings showed that gas reflux with weak acidity is frequent in patients with laryngeal lesions. ${ }^{10}$ Asthma patients with asymptomatic reflux had high amounts of proximal oesophageal acid ${ }^{11}$ whereas in patients with upper airway and additional GORD symptoms, proximal reflux episodes were frequent and correlated well with nocturnal cough. ${ }^{12}$ Abnormal proximal acid exposure was also found in $44 \%$ of 34 patients with non-cardiac chest pain. ${ }^{13}$

\section{"Technical difficulties have precluded accu- rate estimation of reflux volume"}

Direct estimation of reflux volume has been attempted using either oesophageal continuous aspiration or oesophageal scintigraphic studies. Aspiration studies could not measure the volume of individual reflux events but collected $2-7 \mathrm{ml}$ refluxate/h during fasting and $9-15 \mathrm{ml}$ refluxate/h in the postprandial period. ${ }^{14-17}$ These studies failed to show substantial differences in postprandial aspirated volumes between healthy controls and patients with GORD. ${ }^{14}{ }^{15}$ In combined pH-metry-scintigraphic studies, reflux volume was inferred based on calculation of the increment in oesophageal isotopic counts above baseline and was marginally higher in patients with GORD compared with normal controls. ${ }^{18}$

Parameters measured using other techniques allow speculation on the volume of reflux. Examples of these are measurement of the proximal extent of reflux by multiple pH-metry or oesophageal intraluminal impedance; extension of the manometric common cavity phenomenon and, more recently, measurement of the cross sectional area of the oesophageal lumen using high frequency ultrasound.

The proximal extent of reflux has been measured using multiple $\mathrm{pH}$ sensors. ${ }^{19-23}$ Analysis of orally progressing changes in oesophageal $\mathrm{pH}$ provides an idea of velocity and proximal spreading of acid reflux. Weusten et al first suggested that perception of reflux symptoms might depend on the proximal extent of the refluxate. $^{21}$ In GORD patients, symptomatic reflux events had a higher median proximal extent than asymptomatic reflux. The same investigators found that more reflux events have a longer distal duration and reach a higher proximal level in patients with GORD than in

Abbreviations: GORD, gastro-oesophageal reflux disease 
normal controls. ${ }^{20}$ They suggested a correlation between these two parameters and hypothesised that a relatively large volume of the refluxate might account for both observations. More recently, Cicala et al confirmed the higher proximal extent of reflux in patients with GORD; particularly interesting was the increased rate and perception of proximal reflux in patients with non-erosive GORD with otherwise normal distal acid exposure. ${ }^{23}$

\section{"The proximal extent of reflux has been measured using multiple $\mathrm{pH}$ sensors"}

Recent studies using intraluminal ultrasound measured the distal oesophageal cross sectional area during distensions by water swallows or spontaneous reflux events. The maximal cross sectional areas of the distal oesophagus during water swallows with boluses of 1, 5, 10, 15, and $20 \mathrm{ml}$ were $54,101,175,235$, and $246 \mathrm{~mm}^{2}$, respectively, whereas the median cross sectional area during liquid gastrooesophageal reflux was $44.1 \mathrm{~mm}^{2}$, suggesting that distension of the oesophagus during physiological gastro-oesophageal reflux is relatively small. ${ }^{24}$ In patients with GORD, however, reflux events associated with symptoms (heartburn or regurgitation) induced larger distal distensions than asymptomatic reflux events. ${ }^{25} 26$

The volume and proximal extent of reflux probably results from a balance between different factors, including characteristics of the gastric contents, permissive role or compliance of the oesophagogastric junction, gastrooesophageal pressure gradient, physical properties of the refluxate, and the resistance opposed by gravity and/or motor activity in the oesophageal body.

\section{"The volume and proximal extent of reflux probably} results from a balance between different factors"

Recent analysis of ambulatory pH-impedance recordings from our laboratory illustrated the relationship between the degree of gastric fullness and proximal extent of reflux. During the first hour after a meal, 20\% more reflux episodes reach a higher proximal extent than during the fasting period (personal observation). The viscosity of gastric contents is higher early after a meal. ${ }^{27}{ }^{28}$ The use of thickened milks in babies with GORD reduces both the number and proximal extent of reflux..$^{29-32}$ Increased compliance of the oesophagogastric junction, observed in patients with a hiatus hernia, may facilitate gastro-oesophageal flow even with a low gastro-oesophageal pressure gradient. ${ }^{33}{ }^{34}$ Ambulatory manometric-pH studies showed occurrence of acid reflux during increased gastro-oesophageal pressure gradient (straining). Straining significantly increases the likelihood of reflux during transient lower oesophageal sphincter (LOS) relaxation. ${ }^{35}{ }^{36}$ In GORD patients, straining plays a significant role, particularly in the presence of a hiatus hernia and more severe degrees of oesophagitis. ${ }^{37-39}$ Interestingly, although the presence of gas in the refluxate might increase the total volume and contribute to oesophageal distension, it does not influence the proximal extent of liquid reflux. ${ }^{40}$

Gravity appears to be a less significant parameter with regard to migration of spontaneous acid reflux events. In 24 hour multiple $\mathrm{pH}$ studies, the percentage of reflux episodes that reached $15 \mathrm{~cm}$ above the LOS was similar in the upright and supine positions. ${ }^{20} 22$ Similarly, recent $\mathrm{pH}$ impedance studies failed to demonstrate a higher proximal extent of supine reflux episodes. ${ }^{40}$

Oesophageal body motility may be relevant for the initial proximal extent of reflux and the time that the refluxate remains in the proximal oesophagus (proximal clearance).
Two major components of oesophageal body motility should be considered: peristalsis and tone. Acid reflux can reach $15 \mathrm{~cm}$ above the LOS in approximately 6.8-21 seconds. ${ }^{20}$ On the other hand, the time from acid reflux to first peristaltic contractions was described as approximately 21-64 seconds in normal subjects and 55-119 seconds in patients with GORD. ${ }^{41}{ }^{42}$ These data suggest that primary or secondary peristalsis has less impact on the initial proximal extent of reflux but determines the permanence of the refluxate in the proximal oesophagus. On the other hand, oesophageal tone may influence the initial proximal extent of reflux. Recent studies in subjects without GORD have shown that after eating, highly acidic unbuffered gastric juice is present at the gastro-oesophageal junction. ${ }^{43}$ Furthermore, the number of acid reflux events and acid exposure at $0.5 \mathrm{~cm}$ above the squamocolumnar junction is $5-10$ times higher than $5 \mathrm{~cm}$ more proximally. ${ }^{44}$ The mechanism that restricts gastric contents to this area is not completely clear. In normal subjects, distal acid reflux either causes no change or provokes a slight increase in oesophageal tone more proximally. In patients with oesophagitis, such an increase in tone is less common. ${ }^{45}$ These data suggest that restriction of gastric contents to the oesophagogastric junction area may be helped by normal tone in the distal oesophageal body. The distal oesophagus has a higher resting tone but is more compliant to further distension than the proximal striated muscle oesophagus. ${ }^{46}$ These factors may influence the initial proximal extent, accumulation of the refluxate in different oesophageal areas, and perception of reflux. Theoretically, patients with a more tonic oesophagus may have homogeneous proximal migration and distribution of the refluxate to the proximal oesophagus whereas patients with a more compliant distal oesophagus may accumulate the same volume of refluxate more distally. Different compliance and regional variations in sensory innervation may also explain the increased perception of distension of the proximal oesophagus. ${ }^{46}$ For example, patients with non-erosive GORD have an increased perception of proximal acid reflux compared with patients with distal oesophagitis. ${ }^{23}$

\section{"Oesophageal tone may influence the initial proximal extent of reflux"}

Several experimental studies have assessed the effect of reflux volume on proximal extent, oesophageal clearance, and symptom perception. Vicente et al demonstrated in piglets that oesophageal acid clearance is more volume dependent than motility dependent. ${ }^{47}$ Thompson et al measured secondary peristaltic and upper oesophageal sphincter responses during intraluminal infusion of increasing volumes of $\mathrm{HCl}$, saline, or balloon distensions. All of these stimuli produced similar responses, suggesting that the principal stimulus for upper oesophageal clearance is intraluminal distension. ${ }^{48}$ Orr et al simulated reflux in healthy subjects by perfusing $\mathrm{l}$ and $3 \mathrm{ml}$ of acid into the distal oesophagus. Both the higher volume and sleep increased the incidence of proximal migration. ${ }^{49}$

The relevance of reflux volume on symptom perception can be inferred from studies with intraoesophageal balloon distensions. ${ }^{50}$ The oesophageal sensation increases linearly with increasing balloon volumes. ${ }^{51}$ However, reflux volume is not the only mechanism for symptoms perception. Hypersensitivity and hyperalgesia play significant roles $^{52} 53$ and central sensitisation has been proposed as an important mechanism contributing to gastro-oesophageal reflux induced symptoms. ${ }^{54}$

Quantification of gastro-oesophageal reflux volume and/or proximal extent can be helpful to assess the severity of 
functional and/or anatomical abnormalities of the antireflux barrier and to evaluate the efficiency of antireflux therapies.

In this issue of Gut, Cicala and colleagues ${ }^{55}$ used multiple $\mathrm{pH}$ measurements to assess the proximal spread of reflux in nine patients with GORD before and six months after an endoscopic antireflux procedure (Gatekeeper) (see page 183). They found significant improvement in symptom scores without normalisation of distal acid exposure. However, the middle and proximal number of reflux events and acid exposure decreased significantly in all patients at six months. Did the "Gatekeeper" procedure reduce the volume of reflux? Probably yes. Although pH-metry does not measure volume of reflux, a consistent reduction in proximal detection of acid without a significant decrease in distal acid exposure would suggest so. Either the volume of reflux was smaller or the refluxate accumulated distally. It is possible that the intramural material injected with the antireflux procedure decreased oesophagogastric junction compliance, resulting in increased resistance to retrograde flow of gastric material. Preliminary data from our institution suggest decreased distensibility of the oesophagogastric junction measured with a barostat after the antireflux radiofrequency Stretta procedure.

\section{"Determination of the volume of reflux will help to better understand the pathophysiology of GORD and to evaluate the efficacy of antireflux treatments"}

In summary, the volume of reflux may be important by increasing the total amount of highly concentrated damaging substances, either by prolonging distal mucosal exposure due to slow clearance or by expanding to more proximal areas. Furthermore, volume by itself may be relevant due to distension of the oesophagus. To date, it has not been possible to accurately measure the volume of gastrooesophageal reflux. However, ultrasound measurements of cross sectional areas at different oesophageal levels together with estimation of the proximal extent of reflux using impedance may allow geometric reconstruction and accurate calculation of reflux volumes in the near future. In the meantime, the proximal extent of reflux can be used as a surrogate for reflux volume and has shown to be associated with typical and extraoesophageal GORD symptoms. Determination of the volume of reflux will help to better understand the pathophysiology of GORD and to evaluate the efficacy of antireflux treatments.

\section{ACKNOWLEDGEMENTS}

This work was supported by grants of the F.W.O and of the "Geconcerteerde Onderzoeksactie" of the University of Leuven.

Conflict of interest: None declared.

\section{REFERENCES}

1 Demeester TR, Johnson LF, Joseph GJ, et al. Patterns of gastroesophageal reflux in health and disease. Ann Surg 1976;184:459-70.

2 Kahrilas PJ. GERD pathogenesis, pathophysiology, and clinical manifestations. Cleve Clin J Med 2003;70(suppl 5):S4-19.

3 Shay SS, Johnson LF, Richter JE. Acid rereflux: a review, emphasizing detection by impedance, manometry, and scintigraphy, and the impact on acid clearing pathophysiology as well as interpreting the $\mathrm{pH}$ record. Dig Dis Sci 2003;48: 1-9.

4 Jacob P, Kahrilas PJ, Herzon G. Proximal esophageal pH-metry in patients with 'reflux laryngitis'. Gastroenterology 1991; 100:305-10.

5 Katz PO. Ambulatory esophageal and hypopharyngeal $\mathrm{pH}$ monitoring in patients with hoarseness. Am J Gastroenterol 1990;85:38-40.

6 Ulualp SO, Toohill RJ, Hoffmann R, et al. Pharyngeal $\mathrm{pH}$ monitoring in patients with posterior laryngitis. Otolaryngol Head Neck Surg 1999;120:672-7.

7 Shaker R, Milbrath M, Ren J, et al. Esophagopharyngeal distribution of refluxed gastric acid in patients with reflux laryngitis. Gastroenterology 1995; 109:1575-82.

8 Vaezi MF, Schroeder PL, Richter JE. Reproducibility of proximal probe $\mathrm{pH}$ parameters in 24-hour ambulatory esophageal $\mathrm{pH}$ monitoring. Am J Gastroenterol 1997;92:825-9.
9 Cool M, Poelmans J, Feenstra L, et al. Characteristics and clinical relevance of proximal esophageal pH monitoring. Am J Gastroenterol 2004 (in press).

10 Kawamura O, Aslam M, Rittmann T, et al. Physical and pH properties of gastroesophagopharyngeal refluxate. A 24-hour simultaneous ambulatory impedance and pH monitoring study. Am J Gastroenterol 2004;99:1000-10.

11 Harding SM, Guzzo MR, Richter JE. The prevalence of gastroesophageal reflux in asthma patients without reflux symptoms. Am J Respir Crit Care Med 2000; 162:34-9.

12 Tomonaga T, Awad ZT, Filipi CJ, et al. Symptom predictability of refluxinduced respiratory disease. Dig Dis Sci 2002;47:9-14

13 Gastal OL, Castell JA, Castell DO. Frequency and site of gastroesophageal reflux in patients with chest symptoms. Studies using proximal and distal $\mathrm{pH}$ monitoring. Chest 1994;106:1793-6.

14 Mittal RK, Reuben A, Whitney JO, et al. Do bile acids reflux into the esophagus? A study in normal subjects and patients with gastroesophageal reflux disease. Gastroenterology 1987;92:371-5.

15 Stein HJ, Feussner H, Kaver W, et al. Alkaline gastroesophageal reflux. Assessment by ambulatory esophageal aspiration and $\mathrm{pH}$ monitoring. Am J Surg 1994;167:163-8

16 Stipa F, Stein HJ, Feussner H, et al. Assessment of non-acid esophageal reflux. Comparison between long-term reflux aspiration test and fiberoptic bilirubin monitoring. Dis Esophagus 1997;10:24-8.

17 Kaver WK, Peters JH, DeMeester TR, et al. Composition and concentration of bile acid reflux into the esophagus of patients with gastroesophageal reflux disease. Surgery 1997;122:874-81.

18 Shay SS, Abreu SH, Tsuchida A. Scintigraphy in gastroesophageal reflux disease. A comparison to endoscopy, LESp, and 24-h pH score, as well as to simultaneous pH monitoring. Am J Gastroenterol 1992;87:1094-101.

19 Shaker R, Dodds WJ, Helm JF, et al. Regional esophageal distribution and clearance of refluxed gastric acid. Gastroenterology 1991;101:355-9.

20 Weusten BL, Akkermans LM, vanBerge-Henegouwen GP, et al. Dynamic characteristic of gastro-oesophageal reflux in ambulatory patients with gastrooesophageal reflux disease and normal control subjects. Scand J Gastroenterol 1995;30:731-7.

21 Weusten BL, Akkermans LM, vanBerge-Henegouwen GP, et al. Symptom perception in gastroesophageal reflux disease is dependent on spatiotemporal reflux characteristics. Gastroenterology 1995; 108:1739-44.

22 Weusten BL, Akkermans LM, vanBerge-Henegouwen GP, et al. Spatiotemporal characteristics of physiological gastroesophageal reflux. Am J Physiol 1994;266:G357-62.

23 Cicala M, Emerenziani S, Caviglia R, et al. Intra-oesophageal distribution and perception of acid reflux in patients with non-erosive gastro-oesophageal reflux disease. Aliment Pharmacol Ther 2003;18:605-13.

24 Rhee PL, Liu J, Puckett JL, et al. Measuring esophageal distension by highfrequency intraluminal ultrasound probe. Am J Physiol Gastrointest Liver Physiol 2002;283:G886-92.

25 Tipnis NA, Mittal YR, Liu J, et al. Gastroesophageal reflux induced distension of esophagus. Comparison between symptomatic and asymptomatic reflux episodes. Gastroenterology 2004; 126:A-111.

26 Tipnis NA, Mittal YR, Liu J, et al. Reflux through an ultrasonographic eye. Measuring esophageal distension during spontaneous gastroesophageal reflux episodes. Gastroenterology 2004;126:A-320.

27 Marciani L, Gowland PA, Spiller RC, et al. Effect of meal viscosity and nutrients on satiety, intragastric dilution, and emptying assessed by MRI. Am J Physiol Gastrointest Liver Physiol 2001;280:G1227-33.

28 Marciani L, Gowland PA, Spiller RC, et al. Gastric response to increased meal viscosity assessed by echo-planar magnetic resonance imaging in humans. J Nutr 2000;130:122-7.

29 Orenstein SR, Magill HL, Brooks P. Thickening of infant feedings for therapy of gastroesophageal reflux. J Pediatr 1987;110:181-6.

30 Vanderhoof JA, Moran JR, Harris CL, et al. Efficacy of a pre-thickened infant formula. a multicenter, double-blind, randomized, placebo-controlled parallel group trial in 104 infants with symptomatic gastroesophageal reflux. Clin Pediatr (Phila) 2003;42:483-95.

31 Vandenplas $Y$, Lifshitz JZ, Orenstein S, et al. Nutritional management of regurgitation in infants. J Am Coll Nutr 1998;17:308-16.

32 Wenzl TG, Schneider S, Scheele F, et al. Effects of thickened feeding on gastroesophageal reflux in infants. A placebo-controlled crossover study using intraluminal impedance. Pediatrics 2003;111:e355-9.

33 Pandolfino JE, Shi G, Trueworthy B, et al. Esophagogastric junction opening during relaxation distinguishes nonhernia reflux patients, hernia patients, and normal subjects. Gastroenterology 2003;125:1018-24.

34 Pandolfino JE, Shi G, Curry J, et al. Esophagogastric junction distensibility. A factor contributing to sphincter incompetence. Am J Physiol Gastrointest Liver Physiol 2002;282:G1052-8.

35 Schoeman MN, Tippett MD, Akkermans LM, et al. Mechanisms of gastroesophageal reflux in ambulant healthy human subjects. Gastroenterology 1995; 108:83-91.

36 Barham CP, Gotley DC, Miller R, et al. Pressure events surrounding oesophageal acid reflux episodes and acid clearance in ambulant healthy volunteers. Gut 1993;34:444-9.

37 Penagini R, Schoeman MN, Dent J, et al. Motor events underlying gastrooesophageal reflux in ambulant patients with reflux oesophagitis. Neurogastroenterol Motil 1996;8:131-41.

38 Barham CP, Gotley DC, Mills A, et al. Precipitating causes of acid reflux episodes in ambulant patients with gastro-oesophageal reflux disease. Gut 1995;36:505-10.

39 van Herwaarden MA, Samsom M, Smout AJ. Excess gastroesophageal reflux in patients with hiatus hernia is caused by mechanisms other than transient LES relaxations. Gastroenterology 2000;119:1439-46. 
40 Sifrim D, Holloway R, Silny J, et al. Acid, nonacid, and gas reflux in patients with gastroesophageal reflux disease during ambulatory 24 -hour $\mathrm{pH}-$ impedance recordings. Gastroenterology 2001;120:1588-98.

41 Barham CP, Gotley DC, Mills A, et al. Oesophageal acid clearance in patients with severe reflux oesophagitis. Br J Surg 1995:82:333-7.

42 Barham CP, Gotley DC, Miller R, et al. Ambulatory measurement of oesophageal function. Clinical use of a new $\mathrm{pH}$ and motility recording system. Br J Surg 1992;79: 1056-60.

43 Fletcher J, Wirz A, Young J, et al. Unbuffered highly acidic gastric juice exists at the gastroesophageal junction after a meal. Gastroenterology $2001 ; 121: 775-83$

44 Fletcher J, Wirz A, Henry E, et al. Studies of acid exposure immediately above the gastro-oesophageal squamocolumnar junction. Evidence of short segment reflux. Gut 2004;53:168-73.

45 Sifrim D, Tack J, Lerut T, et al. Transient lower esophageal sphincter relaxations and esophageal body muscular contractile response in reflux esophagitis. Dig Dis Sci 2000;45:1293-300.

46 Mayrand S, Diamant NE. Measurement of human esophageal tone in vivo. Gastroenterology 1993;105:1411-20.

47 Vicente Y, da Rocha C, Hernandez-Peredo G, et al. Esophageal acid clearance. More volume-dependent than motility-dependent in healthy piglets. J Pediatr Gastroenterol Nutr 2002;35:173-9.
48 Thompson DG, Andreollo NA, McIntyre AS, et al. Studies of the oesophageal clearance responses to intraluminal acid. Gut 1988;29:881-5

49 Orr WC, Elsenbruch S, Harnish MJ, et al. Proximal migration of esophageal acid perfusions during waking and sleep. Am J Gastroenterol 2000;95:37-42.

50 Barish CF, Castell DO, Richter JE. Graded esophageal balloon distention. A new provocative test for noncardiac chest pain. Dig Dis Sci 1986;31:1292-8

51 Smout AJ, Devore MS, Dalton CB, et al. Effects of nifedipine on esophageal tone and perception of esophageal distension. Dig Dis Sci 1992;37:598-602.

52 Rao SS, Gregersen H, Hayek B, et al. Unexplained chest pain. The hypersensitive, hyperreactive, and poorly compliant esophagus. Ann Intern Med 1996;124:950-8.

53 Rao SS, Hayek B, Summers RW. Functional chest pain of esophageal origin. hyperalgesia or motor dysfunction. Am J Gastroenterol 2001;96:2584-9.

54 Sarkar S, Aziz Q, Woolf CJ, et al. Contribution of central sensitisation to the development of non-cardiac chest pain. Lancet 2000;356:1154-9.

55 Cicala M, Gabbrielli A, Emerenziani S, et al. Effect of endoscopic augmentation of the lower oesophageal sphincter (Gatekeeper reflux repair system) on intraoesophageal dynamic characteristics of acid reflux. Gut 2005;54:183-6.

\section{EDITOR'S QUIZ: GI SNAPSHOT}

\section{Caecal tumour with hepatic metastases?}

Robin Spiller, Editor

\section{Clinical presentation}

A 57 year old farmer presented with a four day history of jaundice, fever, chills, nausea, and right upper and lower quadrant pain. He had just returned from India a month earlier. There was no relevant past medical, surgical, family, or social history. Clinically, he looked wasted and had a temperature of $38.5^{\circ} \mathrm{C}$. Tenderness was elicited in the right hypochondrium and there was a palpable tender colon in the right iliac fossa. Blood investigations revealed a raised erythrocyte sedimentation rate of 73 and abnormal liver function tests (bilirubin $47 \mu \mathrm{mol} / \mathrm{l}$, alkaline phosphatase $314 \mathrm{U} / \mathrm{l}$, gamma glutamyl transferase $263 \mathrm{U} / \mathrm{l}$, aspartate aminotransferase $66 \mathrm{U} / \mathrm{l}$, and alanine aminotransferase $108 \mathrm{U} / \mathrm{l})$. Blood and urine cultures revealed no growth. Mantoux and human immunodeficiency virus testing was negative. Further serology for an infectious aetiology was sought.
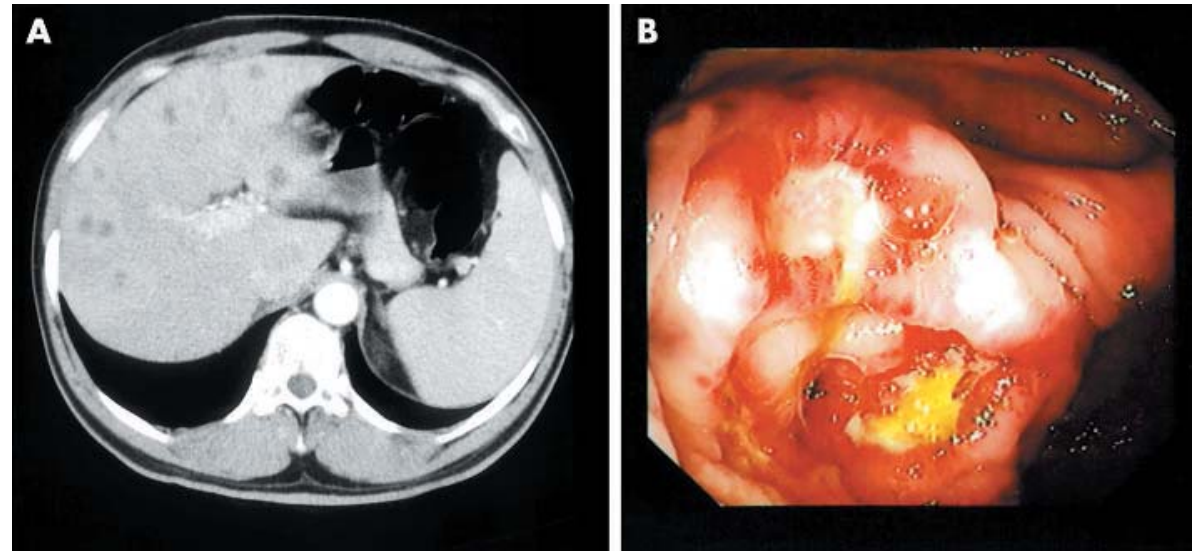

Figure 1 Computed tomography scan (A) and colonoscopy image (B) of the abdomen.

\section{Question}

How do the computed tomography scan of the abdomen and colonoscopy images help in the diagnosis (fig 1)?

See page 200 for answer

This case is submitted by:

S Rajendra

Division of Gastroenterology, Department of Medicine, Royal Perak College of Medicine, Ipoh, Malaysia

K Kutty

Department of Pathology, Sri Kota Hospital, Klang, Malaysia

Correspondence to: Dr S Rajendra, Division of Gastroenterology, Department of Medicine, Royal Perak College of Medicine, 3 Jalan Greentown, 30450 Ipoh, Malaysia; shanraj@pd.jaring.my

doi: 10.1136/gut.2004.046102

l Computed tomography scan (A) and colonoscopy image(B) of the abdomen. 